Article

\title{
Contrastive Analysis of the Raman Spectra of Polychlorinated Benzene: Hexachlorobenzene and Benzene
}

\author{
Xian Zhang ${ }^{1}$, Qin Zhou ${ }^{1,2}$, Yu Huang ${ }^{1}$, Zhengcao Li ${ }^{1}$ and Zhengjun Zhang ${ }^{1, *}$ \\ 1 Advanced Materials Laboratory, Department of Materials Science and Engineering, Tsinghua \\ University, Beijing 100084, China; E-Mails: xian-zhang09@mails.tsinghua.edu.cn (X.Z.); \\ qinzhou@tsinghua.edu.cn (Q.Z.); huang-y07@mails.tsinghua.edu.cn (Y.H.); \\ zcli@tsinghua.edu.cn (Z.L.) \\ 2 Institute of Nuclear and New Energy Technology, Tsinghua University, Beijing 100084, China \\ * Author to whom correspondence should be addressed; E-Mail: zjzhang@tsinghua.edu.cn; \\ Tel.: +86-010-6277-2233; Fax: +86-010-6277-1160.
}

Received: 17 November 2011; in revised form: 1 December 2011 / Accepted: 5 December 2011 / Published: 8 December 2011

\begin{abstract}
Detection of persistent pollutants such as polychlorinated benzene in environment in trace amounts is challenging, but important. It is more difficult to distinguish homologues and isomers of organic pollutantd when present in trace amounts because of their similar physical and chemical properties. In this work we simulate the Raman spectra of hexachlorobenzene and benzene, and figure out the vibration mode of each main peak. The effect on the Raman spectrum of changing substituents from $\mathrm{H}$ to $\mathrm{Cl}$ is analyzed to reveal the relations between the Raman spectra of homologues and isomers of polychlorinated benzene, which should be helpful for distinguishing one kind of polychlorinated benzene from its homologues and isomers by surface enhanced Raman scattering.
\end{abstract}

Keywords: persistent pollutants; polychlorinated benzene; homologue; isomer; hexachlorobenzene; vibration mode

\section{Introduction}

Persistent organic pollutants (POPs), such as dioxins, polychlorinated biphenyls (PCBs) and polychlorinated benzene etc., are harmful to humans' health, and have seriously polluted the 
environment [1]. In recent years, great research interest has been focused on the detection and removal of these pollutants, in which techniques that are able to detect these compounds in trace amounts are essential. This is because they can accumulate to a high concentration in human bodies through the food chain and cause severe diseases when the concentration exceeds the critical level, even when just just in trace amounts in the environment [1-3]. Currently, the combination of high-resolution gas chromatography (GC) and mass spectrometry (MS) is widely used as a powerful means for the detection of these pollutants. However, the GC/MS method is expensive and time-consuming, and is not able to distinguish homologues [4-7].

Nanostructured materials exhibit many interesting properties and may have potential in the detection of trace amounts of organic pollutants [8-11]. For example, some organics were detected at trace levels by Surface-Enhanced Raman Scattering (SERS), using nanostructures of noble metals $(\mathrm{Cu}, \mathrm{Ag}$ and $\mathrm{Au})$ as the substrate [12-18]. SERS is a technique with high sensitivity, simplicity and fast detection, and it's also capable in the recognition of compounds.

Among the approaches so far available to fabricate SERS-active substrates, glancing angle deposition (GLAD) is a promising one because of its simplicity and effectiveness [19]. Porous films consisting of $\mathrm{Ag}$ isolated nanorods is obtained through GLAD, and found to be excellent SERS substrates for the detection of some organics, with a SERS enhancement of greater than $10^{12}$. The structure and SERS performance of porous Ag film is shown in Figure 1(a,b), respectively.

Figure 1. (a) The SEM image of vertically aligned Ag nanorods deposited on silicon substrates; and (b) Raman spectra of R6G on these Ag nanorods as the SERS substrate, at a concentration of $10^{-8} \mathrm{M}$ and $10^{-10} \mathrm{M}$, respectively.
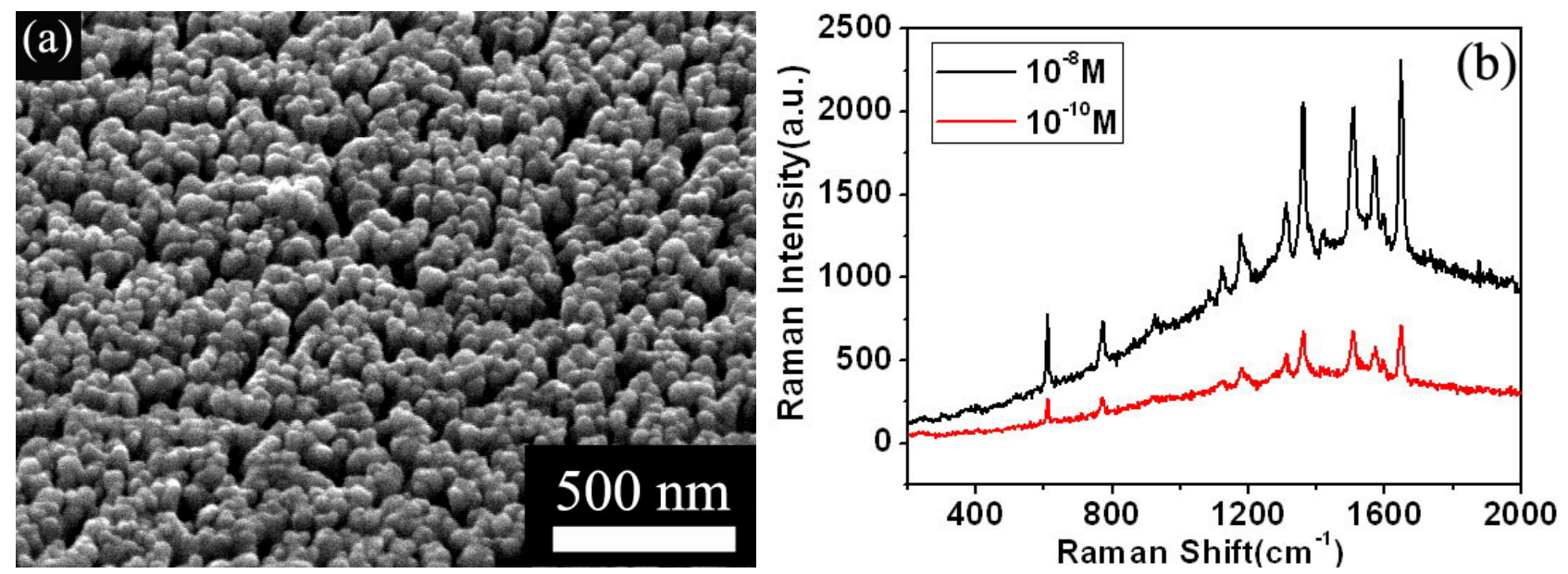

Although the SERS technique could be used to detect trace amounts of polychlorinated benzenes, distinguishing one kind of polychlorinated benzene from its 12 isomers and homologues is still a problem. Indeed, isomers and homologues of organic pollutants have similar physical and chemical properties, thus, they are hard to distinguish, especially in trace amounts. As different isomers and homologues have different vibration modes, their Raman shift corresponding to these vibration mode are different, too. By this way, the SERS method with silver nanorods as a substrate can be used to identify the Raman characteristics of homologues and isomers of polychlorinated benzene, even at trace levels, so it is necessary to analyze the differences and relationships between the Raman spectra 
of each kind of polychlorinated benzene if we want to distinguish each homologue or isomer. As a tentative research topic, we analyzed the Raman spectra of hexachlorobenzene and benzene with their corresponding vibration modes. Here, we report our theoretical study on the Raman spectra of hexachlorobenzene and benzene.

\section{Experimental Procedure}

The Raman spectra of benzene and hexachlorobenzene (HCB) were measured with a Renishaw Raman 100 spectrometer using a $633 \mathrm{~nm}$ He-Ne laser as the excitation source at room temperature. Powders of these compounds are commercially available from the AccuStandard Company. Simulation of these Raman spectra was performed using the Gaussian 03 programme package with the density functional theory, to better understand the vibrational modes observed and figure out fingerprints of these compounds. The simulations were carried out with the Becke's three-parameter hybrid method using the Lee-yang-Parr correlation functional (B3LYP) and the LANL2DZ basis set [20]. The B3LYP functional has been employed with success to simulate the Raman spectra of organic pollutants [21]. The Gaussian View was used to input investigated compounds' data visually.

\section{Results and Discussion}

First of all, the standard Raman spectra of hexachlorobenzene and benzene in the powder state is recorded by the Renishaw Raman spectrometer using a $633 \mathrm{~nm}$ laser as excitation source. Figure 2(a,b) shows the measured Raman spectra of hexachlorobenzene (HCB) and benzene, respectively. Each material has strong peaks at $\sim 1,500 \mathrm{~cm}^{-1}, 1,000 \mathrm{~cm}^{-1}, 650 \mathrm{~cm}^{-1}$, demonstrating the common features of benzene and hexachlorobenzen, but the differences between the Raman spectra of benzene and hexachlorobenzene are obvious. For example: (1) hexachlorobenzene has strong peaks at $377 \mathrm{~cm}^{-1}, 347 \mathrm{~cm}^{-1}, 326 \mathrm{~cm}^{-1}, 219 \mathrm{~cm}^{-1}$; (2) benzene has strong peaks at $3,063 \mathrm{~cm}^{-1}, 2,950 \mathrm{~cm}^{-1}$, $1,177 \mathrm{~cm}^{-1}$. To gain a clear understanding of these features, we performed a simulation using the Gaussian 03 programme package.

Figure 2. Experimental Raman spectrum of (a) hexachlorobenzene; (b) benzene, in powder, with the main peaks marked.
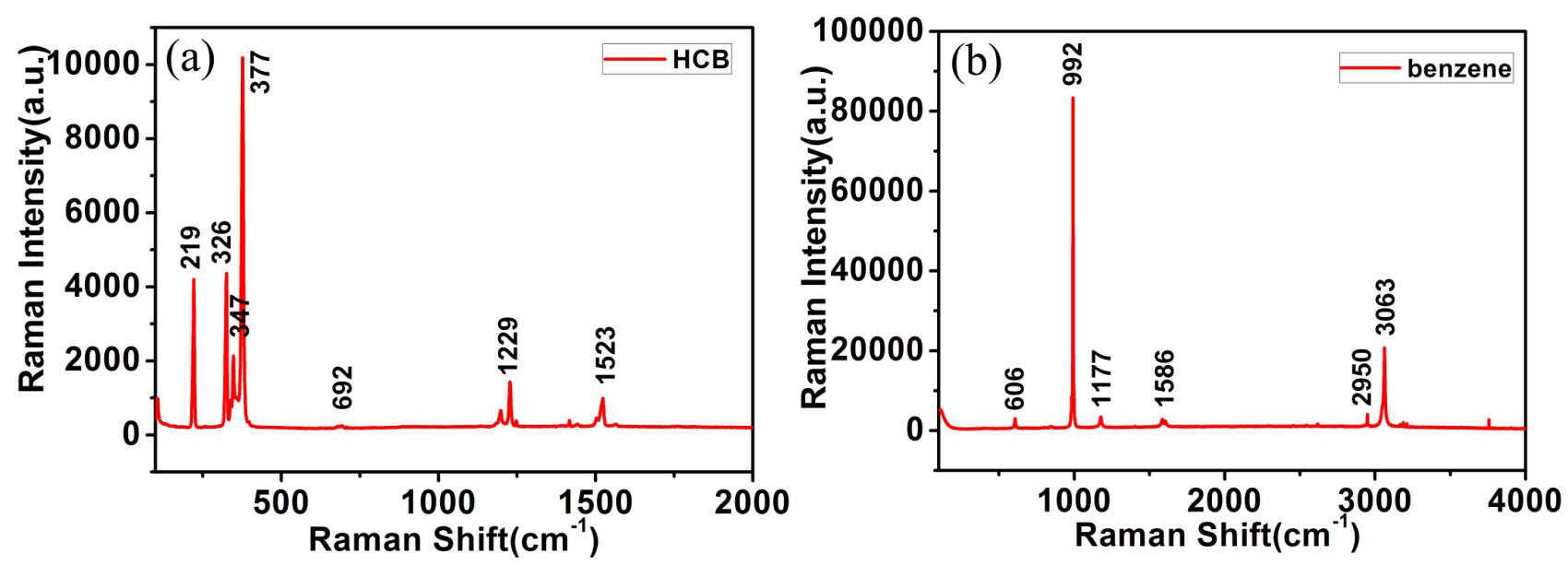
From Figure 2(a), one clearly sees peaks at $\sim 1,523,1,229,692,377,347,326$ and $219 \mathrm{~cm}^{-1}$, demonstrating the feature of HCB. It is found by simulation that the peak at $1,523 \mathrm{~cm}^{-1}$ represents the CCC stretching vibration mode, shown as Figure 3(a); the peak at 1,229 $\mathrm{cm}^{-1}$ represents the benzene ring breathing vibration mode, shown as Figure 3(b); the peak at $692 \mathrm{~cm}^{-1}$ represents the CCC deformation in plane vibration mode, shown as Figure 3(c); the peak at $377 \mathrm{~cm}^{-1}$ represents the $\mathrm{C}-\mathrm{Cl}$ symmetrical stretching vibration mode; the peak at $347 \mathrm{~cm}^{-1}$ represents the benzene ring swing out-of-plane vibration mode; the peak at $326 \mathrm{~cm}^{-1}$ represents the $\mathrm{C}-\mathrm{Cl}$ anti-symmetrical stretching vibration mode; and the peak at $219 \mathrm{~cm}^{-1}$ represents the $\mathrm{C}-\mathrm{Cl}$ shear vibration mode, shown as Figure 3(d).

Figure 3. Illustration of vibration in hexachlorobenzene for: (a) CCC stretching vibration mode; (b) benzene ring breathing vibration mode; (c) CCC deformation in plane vibration mode; (d) $\mathrm{C}-\mathrm{Cl}$ shear vibration mode.

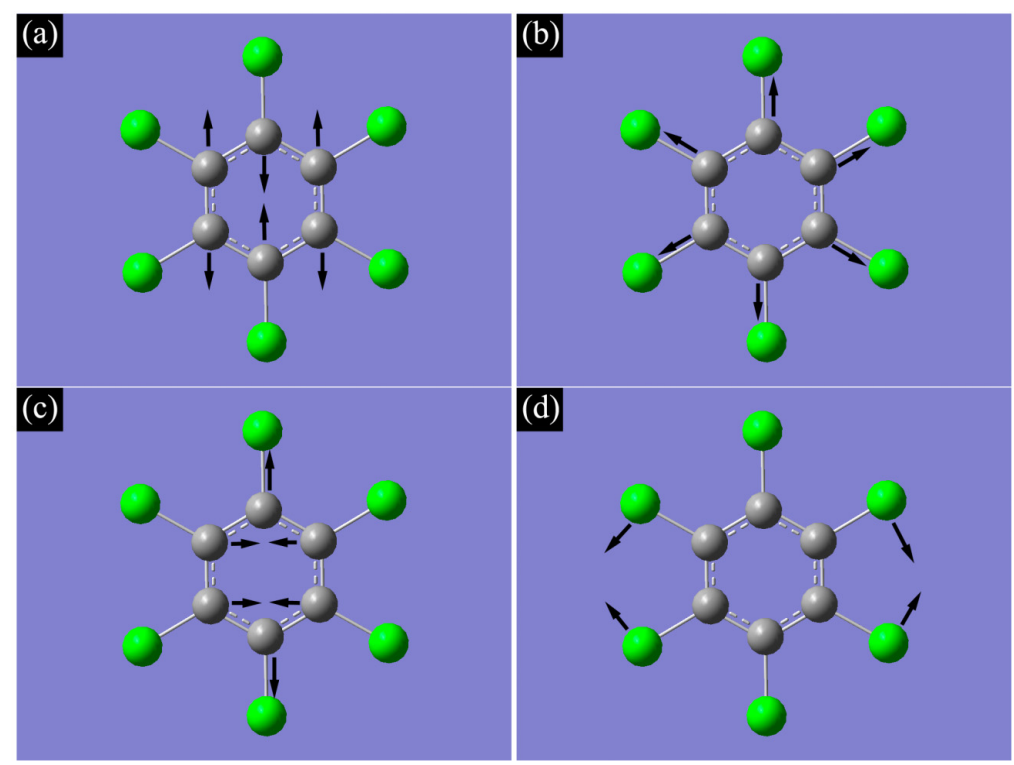

Figure 2(b) shows the measured Raman spectrum of benzene, where the peaks at 3,063, 2,950, $1,586,1,177,992$ and $606 \mathrm{~cm}^{-1}$ represent its characteristic features. It is found by simulation that the peak at $3,063 \mathrm{~cm}^{-1}$ represents the $\mathrm{C}-\mathrm{H}$ symmetrical stretching vibration mode; the peak at $2,950 \mathrm{~cm}^{-1}$ represents $\mathrm{C}-\mathrm{H}$ anti-symmetrical stretching vibration mode; the peak at $1,586 \mathrm{~cm}^{-1}$ represents the $\mathrm{CCC}$ stretching vibration mode; the peak at $1,177 \mathrm{~cm}^{-1}$ represents the $\mathrm{C}-\mathrm{H}$ shear vibration mode; the peak at $992 \mathrm{~cm}^{-1}$ represents the benzene ring breathing vibration mode; the peak at $606 \mathrm{~cm}^{-1}$ represented the $\mathrm{CCC}$ deformation in plane vibration mode.

By contrasting the Raman spectra of $\mathrm{HCB}$ and benzene, it is found that the vibrational Raman shifts just involving $\mathrm{C}$ atoms are stable whether the substituent atom is $\mathrm{Cl}$ or $\mathrm{H}$. For example, the Raman shifts of the CCC stretching vibration modes in $\mathrm{HCB}$ and benzene are $1,523 \mathrm{~cm}^{-1}$ and $1,586 \mathrm{~cm}^{-1}$, respectively. The Raman shifts of the benzene ring breathing vibration mode in HCB and benzene are $1,229 \mathrm{~cm}^{-1}$ and $992 \mathrm{~cm}^{-1}$, respectively. The Raman shifts of CCC deformation in plane vibration mode in HCB and benzene are $692 \mathrm{~cm}^{-1}$ and $606 \mathrm{~cm}^{-1}$, respectively, so recognizing the peaks around $1,500 \mathrm{~cm}^{-1}, 1,000 \mathrm{~cm}^{-1}$ and $650 \mathrm{~cm}^{-1}$ could be an effective way to detect the homologues and isomers of polychlorinated benzene. However, the Raman shift of vibration involving substituent atoms 
depends on the substituent. For example, the $\mathrm{C}-\mathrm{Cl}$ symmetrical stretching vibration mode Raman shift in $\mathrm{HCB}$ is at $377 \mathrm{~cm}^{-1}$, while the Raman shift of the $\mathrm{C}-\mathrm{H}$ symmetrical stretching vibration mode in benzene is at $3,063 \mathrm{~cm}^{-1}$. The Raman shift of the $\mathrm{C}-\mathrm{Cl}$ anti-symmetrical stretching in $\mathrm{HCB}$ is $326 \mathrm{~cm}^{-1}$, while the Raman shift of the $\mathrm{C}-\mathrm{H}$ anti-symmetical stretching in benzene is $2,950 \mathrm{~cm}^{-1}$. The Raman shift of C-Cl shear vibration mode is at $219 \mathrm{~cm}^{-1}$, while the Raman shift of C-H shear vibration mode is at $1,177 \mathrm{~cm}^{-1}$. The Raman shifts of the same kind of vibration involving substituents vary in $\mathrm{HCB}$ and benzene, and the Raman shifts become smaller as the substituent atom changes from $\mathrm{H}$ to $\mathrm{Cl}$, so the Raman shift of vibration involving the substituent atom can help us distinguish one kind of chlorinated benzene from its homologues and isomers.

Additionally it is found for hexachlorobenzene that the Raman shift of vibration involving just $\mathrm{C}$ atoms is around $500-2,000 \mathrm{~cm}^{-1}$, while the Raman shift of vibration involving $\mathrm{Cl}$ substituent atoms is around $100-400 \mathrm{~cm}^{-1}$. Subsequently, the two kinds of vibrations correspond to Raman peaks separated into two bands in hexachlorobenzene, while the Raman peaks of the two kinds of vibration mix into one band in benzene.

\section{Concluding Remarks}

In summary, we demonstrated here an analysis of the Raman spectra and the corresponding vibration modes of hexachlorobenzene and benzene. It is shown that the simulation and analysis of Raman spectra can be a powerful way to detect homologues and isomers of polychlorinated benzene in trace amounts using the SERS technique, which is crucial for the removal of the pollutants.

\section{Acknowledgments}

The authors are grateful for the financial support by the National Natural Science Foundation of China (No. 50931002), and the National Basic Research Program of China (973 Program, No. 2007CB936601).

\section{References}

1. Ross, G. The public health implications of polychlorinated biphenyls (PCBs) in the environment. Ecotoxicol. Environ. Safety 2004, 59, 275-291.

2. Cicchetti, D.V.; Kaufman, A.S.; Sparrow, S.S. The relationship between prenatal and postnatal exposure to polychlorinated biphenyls (PCBs) and cognitive, neuropsychological, and behavioral deficits: A critical appraisal. Psychol. Schools 2004, 41, 589-624.

3. Ohtsubo, Y.; Kudo, T.; Tsuda, M.; Nagata, Y. Strategies for bioremediation of polychlorinated biphenyls. Appl. Microbiol. Biotech. 2004, 65, 250-258.

4. Pitarch, E.; Serrano, R.; Lopez, F.J.; Hernandez, F. Rapid multiresidue determination of organochlorine and organophosphorus compounds in human serum by solid-phase extraction and gas chromatography coupled to tandem mass spectrometry. Anal. Bioanal. Chem. 2003, 376, 189-197.

5. Namiesnik, J.; Zygmunt, B. Selected concentration techniques for gas chromatographic analysis of environmental samples. Chromatographia 2002, 56, S9-S18. 
6. Hong, J.E.; Pyo, H.; Park, S.J.; Lee, W. Determination of hydroxy-PCBs in urine by gas chromatography/mass spectrometry with solid-phase extraction and derivatization. Anal. Chim. Acta 2005, 531, 249-256.

7. Barra, R.; Cisternas, M.; Suarez, C.; Araneda, A.; Pinones, O.; Popp, P. PCBs and HCHs in a saltmarsh sediment record from South-Central Chile: Use of tsunami signatures and Cs-137 fallout as temporal markers. Chemosphere 2004, 55, 965-972.

8. Chu, H.Y.; Liu, Y.J.; Huang, Y.W.; Zhao, Y.P. A high sensitive fiber SERS probe based on silver nanorod arrays. Opt. Exp. 2007, 15, 12230-12239.

9. Sun, X.Z.; Lin, L.H.; Li, Z.C.; Zhang, Z.J.; Feng, J.Y. Novel Ag-Cu substrates for surfaceenhanced Raman scattering. Mater. Lett. 2009, 63, 2306-2308.

10. Isola, N.R.; Stokes, D.L.; Vo-Dinh, T. Surface enhanced Raman gene probe for HIV detection. Anal. Chem. 1998, 70, 1352-1356.

11. Tripp, R.A.; Dluhy, R.A.; Zhao, Y. Novel nanostructures for SERS biosensing. Nano Today 2008, 3, 31-37.

12. Zhao, Y.P.; Chaney, S.B.; Zhang, Z.Y. Absorbance spectra of aligned Ag nanorod arrays prepared by oblique angle deposition. J. Appl. Phys. 2006, 100, 063527.

13. Tan, R.Z.; Agarwal, A.; Balasubramanian, N.; Kwong, D.L.; Jiang, Y.; Widjaja, E.; Garland, A. 3D arrays of SERS substrate for ultrasensitive molecular detection. Sens. Actuat. A Phys. 2007, 139, 36-41.

14. Moskovits, M. Surzface-enhanced spectroscopy. Rev. Modern Phys. 1985, 57, 783-826.

15. Kudelski, A. Analytical applications of Raman spectroscopy. Talanta 2008, 76, 1-8.

16. Vodinh, T.; Houck, K.; Stokes, D.L. Surface-enhanced Raman gene probes. Anal. Chem. 1994, 66, 3379-3383.

17. Hering, K.; Cialla, D.; Ackermann, K.; Dorfer, T.; Moller, R.; Schneidewind, H.; Mattheis, R.; Fritzsche, W.; Rosch, P; Popp, J. SERS: A versatile tool in chemical and biochemical diagnostics. Anal. Bioanal. Chem. 2008, 390, 113-124.

18. Zhang, X.Y.; Zhao, J.; Whitney, A.V.; Elam, J.W.; Van Duyne, R.P. Ultrastable substrates for surface-enhanced Raman spectroscopy: A12O3 overlayers fabricated by atomic layer deposition yield improved anthrax biomarker detection. J. Am. Chem. Soc. 2006, 128, 10304-10309.

19. Zhou, Q.; Li, Z.C.; Yang, Y.; Zhang, Z.J. Arrays of aligned, single crystalline silver nanorods for trace amount detection. J. Phys. D Appl. Phys. 2008, 41, 152007.

20. Fleming, G.D.; Golsio, I.; Aracena, A.; Celis, F.; Vera, L.; Koch, R.; Campos-Vallette, M. Theoretical surface-enhanced Raman spectra study of substituted benzenes I. Density functional theoretical SERS modelling of benzene and benzonitrile. Spectrochim. Acta A Mol. Biomol. Spectroscopy 2008, 71, 1049-1055.

21. Librando, V.; Alparone. A. The role of electronic properties to the mutagenic activity of 1,6- and 3,6-dinitrobenzo[a]pyrene isomers. J. Hazard. Mater. 2009, 161, 1338-1346.

(C) 2011 by the authors; licensee MDPI, Basel, Switzerland. This article is an open access article distributed under the terms and conditions of the Creative Commons Attribution license (http://creativecommons.org/licenses/by/3.0/). 